\title{
Sobre las universidades
}

\section{SERGIO ESPINOSA PROA*}

El dominio implacable del capital, el Estado y la tecnociencia se cierne sobre la universidad y la cultura en general. El signo de los tiempos concede el triunfo a la mediocridad representada por la que dice ser la eficiencia y el éxito se prescribe en clave empresarial. Las universidades están sometidas a la razón instrumental, la burocratización y la falta de perspectiva. Pareciera que tienen la obligación de justificar su existencia ante el Estado, que por su parte no rinde cuentas claras a la sociedad. Pero las universidades representan en buena medida la visión, el diálogo y el pensamiento de la sociedad; en vez de hallarse postradas deberían de fiscalizar el funcionamiento de las agencias estatales desde una perspectiva ética y política.

*Docente investigador de la Universidad Autónoma de Zacatecas.
1. Está bastante claro que los que corren no son buenos tiempos para la Universidad - ni para la cultura. Infinidad de factores convergen negativamente. El solo hecho de intentar su defensa revela una inexorable declinación. No encontramos demasiados discursos (ni recursos) de renovación, y los pocos que hay no han logrado frenar el deterioro objetivo de estas instituciones: se han burocratizado al extremo y carecen de perspectivas propias. Actúan de forma cada vez más reactiva y servil. No es fácil explicar por qué se ha llegado a tal postración; es un poco el signo de los tiempos. Casi nada escapa a la uniformidad reiterativa y esclavizante que reclama la sumisión a las tres figuras de la dominación: el Capital, el Estado y la Tecnociencia. Las universidades - con crecientes dificultades, y con frecuencia a regañadientes - terminan plegándose a ellas. Es posible que en el pasado esas tres figuras hayan fungido hasta cierto punto como impulsores y propulsores; hoy son pesadas rémoras. Sofocan y aplastan las virtudes de una humanidad hoy más desorientada que nunca. La inteligencia sucumbe ante estandartes tan inconsistentes y baratos como la competitividad y la excelencia; la imaginación se refugia y sobrevive apenas en pequeñas ranuras y pliegues de la institución. Las (apocalípticas) ideas adelantadas por Jean Baudrillard en Cultura y Simulacro (1978) se han materializado de maneras grotescas. Es el triunfo de la mediocridad - disfrazada de eficiencia. Asistimos a lo que Pascal Finkielkraut denominó La derrota del pensamiento (1990). Universidades estandarizadas, inertes, arrasadas por un tipo degradado de razón instrumental, abyectas ante los poderes fácticos, presas del nerviosismo, inseguras y a su modo zalameras: instancias dóciles, resignadas, predecibles, domésticas. ¿Cómo defenderlas?

2. ¿Estará todo perdido? En múltiples aspectos, sí. Inútil disimularlo, diluirlo, minusvalorarlo o mirar a otro lado. La razón instrumental 
se antoja todo poderosa, pues en lugar de necesitar legitimación, en sí misma es, sobre todo en la condición posmoderna, la fuente de toda legitimación; no requiere ser verdadera, ni justa, ni siquiera razonable: basta con que funcione. Y su función esencial es ajustarse sin fricciones a las exigencias del sistema, exigencias que no admiten mascotas (es decir, cuestionamientos, protestas, desbandadas, impugnaciones, desviaciones, anomalías, circunloquios, disidencias...). La razón instrumental es intolerante a muchas cosas y en particular al pensamiento. Imaginemos cuando esa razón se degrada en prácticas meramente mecánico-empresariales: del pensamiento no quedan rastros. No es que el pensamiento sea propiedad privada $y$ registrada de la filosofía - como disciplina no se halla a salvo de su propia mecanización y mercantilización - pero el hecho de que tienda a ser eliminada de los planes de estudio es indicio de un empobrecimiento inquietante. La ignorancia o la mala fe de los «decididores», como los llamó Jean-François Lyotard en su momento (La condición posmoderna, 1979), es insuficiente para comprender la magnitud, el alcance y los límites del proceso. Hemos llegado al punto en el que muchos universitarios, al ocupar puestos internos de decisión, se comportan como los más acérrimos enemigos de la universidad misma. No la defienden ante o frente a las instancias gubernamentales (y su lógica de presión y vasallaje) porque sencillamente se han convertido, de grado o por fuerza, por astuta conveniencia o mera estupidez, en agentes a su servicio.

3. Tampoco se trata de afirmar - sería el colmo de la infatuación - que las universidades sean por sí solas el último o el único reducto del pensamiento; pero es sin lugar a dudas aquello que las define, distingue y caracteriza: eso sin lo cual no es imaginable defensa alguna. Son «marca Patito» (aunque presuman de excelentes y punteras) si no dan muestras de que finalmente, y a pesar de todo, lo hay. Al menos es lo que cualquier sociedad espera de ellas, además de proveer cuadros técnicos y servicios profesionales de cierta calificación (función a la que desde hace tiempo, abierta o soterradamente, se les procura reducir). Es el ajuste irracional a un sistema irracional lo que produce semejante erosión y el consecuente descenso de los niveles de autoexigencia. A su aire, el pensamiento da fe de esta violencia y se abre camino en medio de la devastación universal: se abre camino abriendo caminos. La efervescencia juvenil de los 1960 ha podido ser teorizada como la manifestación más aguda de esta crisis permanente entre el autoritarismo esclerosante y la imaginación creadora. Es lo que Claude Lefort, Cornelius Castoriadis y Edgar Morin, en aquellos años, calificaron como la Brecha: el perpetuo e indecidido choque entre la voluntad de dominio y la potencia instituyente, entre lo reactivo y lo proactivo, entre la esterilidad y la fecundidad, entre el envejecimiento y la jovialidad. Sin las universidades, las fuerzas instituyentes se deterioran y disipan (y ya sabemos lo que les sucede a aquellas en ausencia de éstas). Son capturadas y amordazadas por eso que Marx llamaba el «trabajo muerto». No otra cosa es lo que se pone en juego en la existencia o inexistencia - y en el cultivo o descuido-de las universidades, que operan como lentes de aumento de procesos y conflictos ocurrentes en todo el tejido social.

4. La contienda por (y contra) las universidades afecta todos los estratos del sujeto. La razón instrumental ha llevado y lleva hasta ahora las de ganar porque es, efectiva y empíricamente, la forma dominante de la razón (a sus propios ojos, la única verdadera): en sociedades poco o suficientemente ilustradas, 
la ciencia es la religión, la materialización genérica del espíritu. No extrañará su deslizamiento en fanatismos y supersticiones de cualquier índole: en tanto fenómeno eclesial, encontrará en cada generación sus Hipatias y sus Giordanos, su Galileo y su Servet. Genera día a día una sombra new age bastante idiota que inclusive le sirve para justificar superioridades. Instaura una subjetividad infame: búsqueda patológica del reconocimiento, inflamación de un ego a todas luces declinante o demencial, discursividad babilónica, protagonismo de feria pueblerina. El éxito es el exclusivo norte de la ideología empresarial. Sujetos analgésicos y anestésicos, pagados de sí, plagados de sí, infestados de autoplagios, regidos por la repetición eficaz y la ley del menor esfuerzo. Lo técnico, abandonado así, resulta patético. Tal es la subjetividad afín a la razón instrumental. ¿Hay otra? Naturalmente. Tiene algo que ver con lo paleolítico, lo arcaico, lo premoderno, lo incivil. Es una subjetividad marginal, recatada (y rescatada), solidaria por instinto y no por mandato o corrección política, entusiasmada por generosidad y no por hipnosis mediático-monetaria, desengañada por experiencia y no por pose o renuncia exhibicionista. No la movilizan valores trascendentales pero sí un deseo de aprender y accionar en las condiciones menos peinadas y propiciatorias. Es un deseo literal y figuradamente existencial: desconfianza ante las abstracciones y conciencia de la infinita complejidad de lo concreto.

5. En los sueños de algunos académicos se transparenta la voluntad de romper o cuando menos deslindarse de esa lógica del vasallaje presente en factorías, líneas de ensamblaje, almacenes, penitenciarías, ejércitos, hospitales, conventillos y partidos políticos: sin tener que hundirse en la anarquía, las universidades expresan una suspensión de las compulsiones disciplinarias; sin deificar

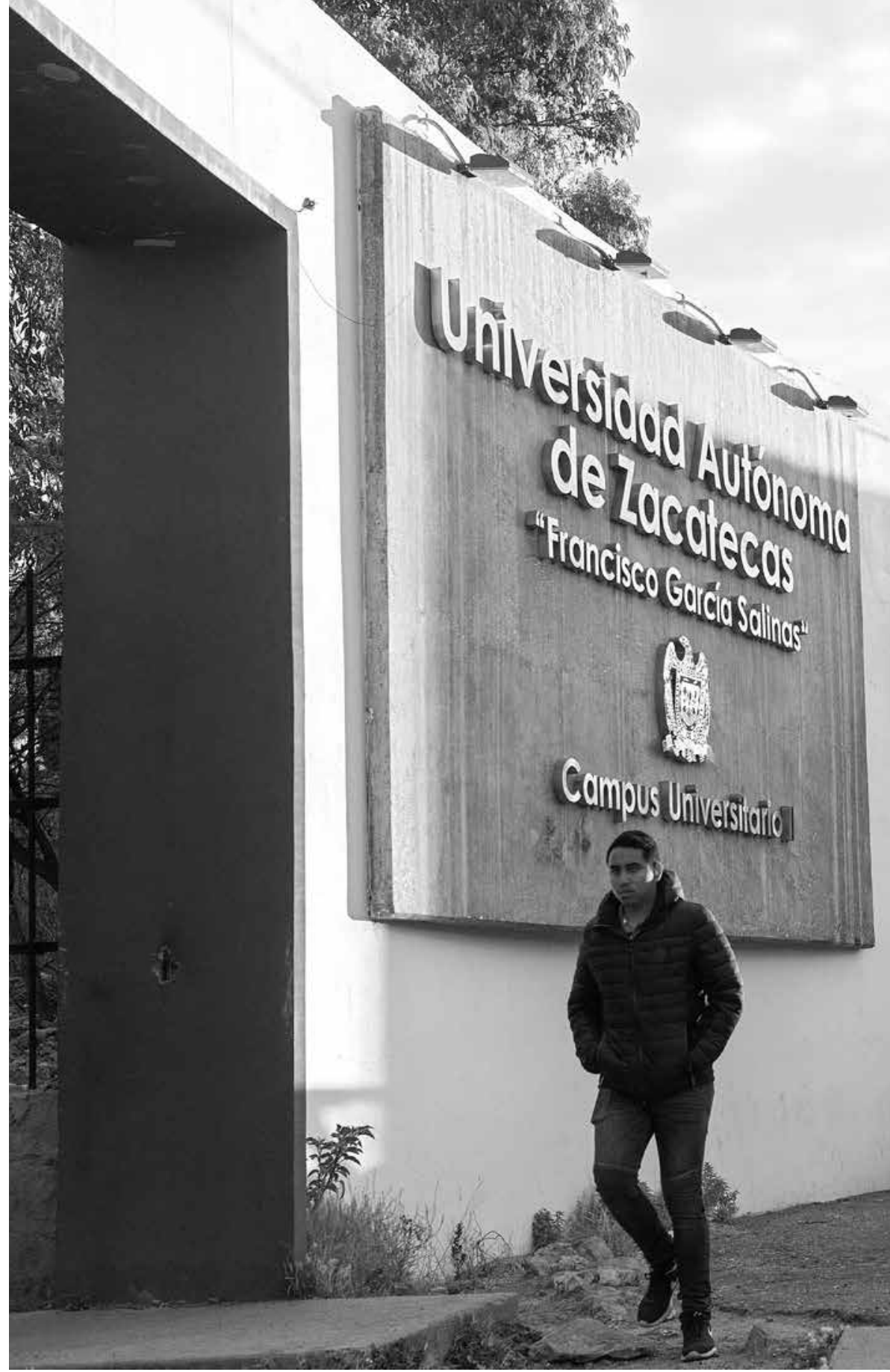

ocios y distracciones, el imperio de la utilidad inmediata queda en ellas relativa y momentáneamente abolido. Se ha llegado a imaginar (es el caso de Luis Porter, de la Universidad Autónoma Metropolitana-Xochimilco) una universidad desburocratizada, realmente autónoma y autorregulada, diversificada y multifuncional, gestora de los espacios sociales - a cuyos sujetos es menester rendir cuentas, y no a los funcionarios gubernamentales-; una universidad «lenta», ajustada a
Las universidades (públicas) se ven forzadas a justificar su existencia misma ante un Estado que se imagina - y actúa - como propietario y señor. Fotografía:

Carlo Román 
los ritmos naturales y capaz de respetar lo aleatorio, el desorden, el impredecible pulso de la reflexión, sus propias inercias y entropías; una universidad ocupada y preocupada por el crecimiento intelectual e incluso afectivo de profesores y estudiantes que deje de lado la obediencia a planes de estudio y asignaturas que además de su rigidez constitutiva entran en imparable obsolescencia; en fin, una universidad viva, saludable, sensible, jovial y solidaria. Seguramente son sueños, pero delatan la presencia de un imaginario que no conviene nunca desestimar. Es que en el mundo regido y administrado por la razón instrumental y sus vástagos, por el Capital y sus tartamudeantes o vociferantes gobiernos, las universidades aparecen como pequeños parques naturales a resguardo de la depredación, islotes o archipiélagos donde aún es posible, a ráfagas, y a pesar de su fragilidad, el pensamiento.

6. Las universidades son los ojos y los oídos de las sociedades, y no sólo de las modernas; esta imagen viene autorizada desde la Grecia del siglo IV antes de la era común y refrendada prácticamente en cada periodo histórico conocido por nuestra civilización. Un ver, un oír, un saber, un aprender y un saber-decir que poseen en sí mismos su propia lógica, su propia justificación, su propia capacidad de concreción y de corrección: su propio modo de pensar (y de actuar). Las rige, desde la $\mathrm{Me}$ tafísica de Aristóteles, y aquí brilla la unanimidad, un deseo de saber. Que sea un deseo y no sólo respuesta a una necesidad experimentada en otra parte de la sociedad se revelará a la postre como algo verdaderamente decisivo: algo que en los tiempos que corren suele olvidarse o menospreciarse. Dicho muy en general, a las universidades, por infinidad de vías, se les ha reducido a su mínima expresión: emergidas con otro propósito, mucho más noble y exigente, ni siquiera fun- cionan a estas fechas como mecanismos de reproducción (ideológica). ¿Por qué ha podido suceder esto? ¿Es resultado de una decadencia natural? ¿Habría una conspiración en su contra? ¿En qué consiste y qué revela su «crisis»?

7. Las raíces son muy profundas, por más que algunas de ellas sean inmediatamente visibles. En cualquier caso, en nuestros días, y en la mayoría de los países «civilizados», se ha llegado a una confusión y a una inversión lamentable de papeles (y de funestas consecuencias): las universidades (públicas) se ven forzadas a justificar su existencia misma ante un Estado que se imagina - y actúa-como propietario y señor. La inversión es total, porque en el origen y por razones de todo tipo es el Estado quien tendría que buscar justificación y legitimación - sobre todo moral, pero no sólo moral - ante una instancia esencial y fundamentalmente libre, que es justo lo propio de las universidades. El Estado tendría que dar razón de sí y someterse al escrutinio de esos «ojos y oídos» que las sociedades se dan a sí mismas por encima y aun en contra de sus instituciones políticas. En breve, es el Estado en sus tres poderes quien periódicamente debe rendir cuentas a las Universidades, que en absoluto son o podrían ser sus «agencias». Son ellas las que han de fiscalizar al Estado, con seguridad no en un sentido técnico-fiduciario pero sí político y ético, es decir: moral. Moral en el mejor sentido de la palabra. ¿Por qué?

8. En una sociedad moderna, el tribunal supremo no es el Estado ni la Razón. En los tiempos que vivimos sólo la razón de Estado mantiene su vigencia y eficacia. Todo el ámbito de lo posible - del poder - tiende a ajustarse a sus criterios, a su lógica de vasallaje. En consecuencia, el Estado incurre en una peculiar ceguera y en una notoria sordera; 
queda anulada por anticipado su capacidad de respuesta, queda extinto su sentido de la responsabilidad, que en cambio le exige a la sociedad en su conjunto y a las universidades en particular. A éstas se les mantiene en una posición similar a la del rehén: sometidas al arbitrio del Estado, a su vigilancia, a su permanente e incluso disimulada intromisión. El problema es entonces que, sometidas y condicionadas por el poder público, las universidades pierden paulatinamente su capacidad de ver y de oír: pierden de vista su capacidad de respuesta y se hunden en la más triste y mecánica servidumbre. El círculo se cierra: la Razón tiene que rendir cuentas al poder público cuando éste ya olvidó cuál era su propósito: cuando se encuentra casi completamente ciego y sordo. ¿Estamos a tiempo de abrirle los ojos, de obligarlo a escuchar razones y no entrar en meras componendas?

9. En una conferencia leída en 1983 en la Cornell University, el filósofo Jacques Derrida se preguntaba: «¿Quién es más fiel a la llamada de la razón? ¿Quién la escucha con un oído más fino? ¿Quién ve mejor la diferencia? ¿Aquel que interroga a su vez e intenta pensar la posibilidad de dicha llamada? o ¿aquel que no quiere oír hablar de una pregunta sobre la razón de la razón? » ${ }^{1}$ Las universidades son el tribunal de la Razón no porque algún dios les haya hecho el obsequio o la gracia, sino porque son la instancia en la cual se inquiere, se cuestiona, se investiga, se pregunta (y dado el caso se impugna) por ese extraño objeto o principio o fin que es la Razón misma. En realidad, son el tribunal de la Razón a condición de evitar, de impedir que ésta se cosifique; la Razón, precisamente, no es un objeto, no es una cosa, ni siquiera una propiedad. La razón designa un punto, o, mejor, un horizonte a partir o desde el cual

\footnotetext{
1 Jaques Derrida, «Las pupilas de la universidad», Suplementos Anthropos, núm. 13, Barcelona, 1989, p. 66.
}

nada podría convertirse en mero objeto de apropiación. Dicho entre paréntesis, hablar por ello de «razón técnica» es un contrasentido: o es razón o es técnica. La razón es un gesto: no una «idea», y menos aún un «valor», sino la suspensión en acto del principio de apropiación, del principio de sujeción, del principio de depredación del mundo. Tal sería su «moral».

10. O, expresado más correctamente, su filosofía (esta vez en cursivas y no entre comillas). Que en el presente las universidades no sean únicamente el lugar de la filosofía - hay algunas en las que o se halla ausente o reducida al mínimo - sino principalmente el asiento de la enseñanza de las ciencias - no, de modo prioritario, de las técnicas - es un hecho digno de reflexión; con todo, su existencia es correlativa a la existencia de la filosofía. Filosofía, desde luego, en su sentido fuerte, no en su uso banal (todas, o la mayoría, tienen, en su portal de internet, un trivial y raquítico párrafo indicando su «filosofía»). ¿Tendría que justificarse su existencia, tendría que invocarse una y otra vez su «derecho» a la existencia? Sería tanto como pedirle, a una persona existente de hecho, que exponga su derecho a tener ojos y oídos y a servirse de ellos según su más leal y soberano querer y entender. En último extremo, y a semejanza de lo correspondiente al Estado ante las universidades, son las ciencias las que tendrían que justificar ante la filosofía - o ante lo que aquí venimos llamando «razón»- su derecho a la existencia (dentro de las universidades). Al menos, las ciencias tal y como se han venido desarrollando, impulsando, fomentando, hasta cristalizar en las tecnociencias, dispositivos de extracción y administración de las energías acumuladas - incluida la fuerza de trabajo - en el planeta (y, por el momento, su entorno más inmediato). 
11. Ninguna universidad se halla exenta de su incorporación en eso que Martin Heidegger calificaba como la Ge-stell - la estructura de movilización y emplazamiento de la cual el Capital y el Estado son manifestación y efecto directo-: se ajustan a sus necesidades con mayor o menor elegancia, pero es preciso señalar que esa no es, en absoluto, su filosofía. Su filosofía, es decir, su deseo, insistamos, es resguardar el principio de razón. Resguardarlo en contra de su instrumentalización, de su uniformización, de su tecnificación, de su politización (en el peor sentido del término: una herramienta en manos de los poderes establecidos, incluso si están presuntamente en contra del statu quo). Tal incorporación a la Ge-stell es inevitable, pero, por fortuna para las sociedades, nunca es total: no puede asimilárselas sin dejar residuos. La incorporación no se produce ya, como lo fue antes, mediante mecanismos tan bastos - pero tan eficientes - como la censura o la prohibición expresa (aunque se siga practicando a discreción): es suficiente -en el caso de las universidades públicas - con estrangular o sobrecondicionar su financiamiento. Añádase a ello la formación maligna de burocracias sólo superficialmente análogas a los comités o consejos académicos internos, encargados de calificar - estimular o desestimular - el rendimiento de los profesores e investigadores. Las invaden por dentro. En suma, las universidades se hallan penetradas o invadidas - diríase violadas - por una lógica heterónoma, sostenidas en vilo por ella, por una mentalidad empresarial o de supermercado, estrecha e inmediatista, que estropea o arruina, intencional o sin querer, su propio funcionamiento como defensa de un principio de razón (nombrémoslo así provisionalmente) al que tendrían que someterse las pretensiones absolutistas del Capital y del (su) Estado, que (in)justamente se yerguen como epítomes incuestionados e incuestio- nables de la razón. En ese contexto, las universidades sucumben una tras otra al autoritarismo de esta idea - sumamente vulgar pero dominante- de razón.

12. ¿De qué se trata entonces? Naturalmente, de defender a la universidad y, en específico, a la universidad pública, que es por obvias razones la más vulnerable a la violencia o a la indiferencia del Estado (y del Capital). La cuestión es mostrar cuál es la «lógica» de tales instituciones, su razón de ser, que es muy distinta a las justificaciones siempre débiles o reactivas que el Capital y su Estado exigen o esperan de ellas. Tampoco, desde luego, es una fábrica de profesionales regida de manera exclusiva por la estructura cambiante y fluctuante del mercado. Formulado en un tono deliberadamente paradójico, como en una viñeta de Escher, diríase que su razón de ser es el ser de la razón. Es en tal virtud que, siguiendo la trayectoria de la tradición filosófica, el alegato de Derrida se halla centrado en la apuesta por una comunidad de pensamiento:

Una comunidad semejante se cuestiona sobre la esencia de la razón y el principio de razón, sobre los valores de fundamental, de principial, de radicalidad, de la arkhé en general, e intenta sacar todas las consecuencias posibles de dicho cuestionamiento. Un pensamiento semejante no es seguro que pueda agrupar a una comunidad o fundar una institución en el sentido tradicional de esas palabras. Ha de re-pensar también aquello que se denomina comunidad e institución. ${ }^{2}$

${ }^{2}$ Ibid., p. 71. Posteriormente, el filósofo declara: «Se trata de prepararse a transformar de forma consecuente los modos de escritura, la escena pedagógica, los procedimientos deco-locución, la relación con las lenguas, con las demás disciplinas, con la institución en general, con su fuera y su dentro». 
13. El cambio de énfasis es importante, pero no afecta a nuestro argumento: llámese «razón», «filosofía»o «pensamiento», lo decisivo es que las universidades públicas se conciban a sí mismas como comunidades autónomas no necesaria ni histéricamente enfrentadas al Estado y al Capital (o al mercado) pero sí dotadas de un estatuto específico consistente en mantenerse abiertas al porvenir; lo cual es un modo de decir que en absoluto podrían ser sirvientas de un poder absoluto encarnado en el Estado, en el capital... o en (alguna) Iglesia. Comunidades del pensamiento, las denomina Derrida, lo que significa libres de sujeciones ideológicas - más o menos inconscientes - y críticas de sus propias inercias y capitulaciones. En ese sentido, no son enemigas (ni amigas, por cierto) del Estado y del Capital, sino, por expresarlo con una suerte de anacronismo, Observatorios del tiempo presente. Por eso son menos críticas que infatigablemente autocríticas: atentas a su deslizamiento en una lógica que sólo pretende «normalizarlas», esto es, como ya se dijo, instrumentalizarlas al servicio de fines ajenos a su esencia o a su vocación fundamental, que es, por todo lo anterior, menos responder a la - muy legítima- necesidad de saber que al -insobornable-deseo de pensar.

14. Rasgos básicos de una comunidad de pensamiento son la transformación incesante de los métodos, la experimentación, la invención y la sensibilidad al acontecimiento. Son instituciones que hacen de la institución un objeto prioritario de examen. La Universidad puede y debe producir conocimiento y preparar al personal adecuado para su conservación, ampliación y transmisión, pero en ello no agota sus fuerzas. Lo esencial es que la universidad no se precipita: le otorga tiempo a la reflexión, lo que significa que en ella el pensamiento sigue su propia cadencia y establece sus muy particulares mediaciones y alianzas metódicas. El pensamiento - del que las ciencias son un subproducto menos deseable que necesario- posee su propio imaginario, su propia ética y su propia estética; se mueve en una atmósfera que no es la de los poderes fácticos (o incluso legítimos). El pensamiento tiene y genera su propia política, a la que las universidades en principio obedecen pero que acaso con demasiada frecuencia olvidan. El elemento del pensamiento apenas podría ser otro que la libertad-«libertad de pensamiento» es un pleonasmo-: tal sería la visión y la misión de las universidades, su sentido profundo, su justificación previa y final, su dignidad y su personalidad. Es que existe una conexión peculiar entre la inspiración y la conspiración; al conspirado lo inspira una idea o una insignia, mientras que el inspirado conspira en primer y en último lugar contra sí mismo: contra las fuerzas que le mantienen más o menos estabilizado en un sí mismo. Es creíble que el inspirado llegue a ser más eficaz; su movimiento contra sí mismo le hace parecer innocuo, por lo que será dejado relativamente en paz. En tal virtud, avanzará más, o con mejor paso, que el conspirador común, que tenderá por su parte a enredarse con sus adláteres y secuaces en una no por hegeliana menos desgastante lucha por el reconocimiento. Al final, sus acciones tendrán un impacto más bien modesto y olvidable.

15. Algo análogo ocurrirá con el pensamiento; éste se topa con la institución, que por regla general le limará las uñas y las fauces para hacerlo socialmente presentable. No choca con ella por fidelidad a una consigna, sino por naturaleza: el pensamiento no «necesita» la libertad porque es una - la más alta, quizás, de sus formas: hay pensamiento porque (y cuando) hay libertad, hay libertad porque (y cuando) hay pensamiento. No por ser 
